\title{
Herederas del pensamiento Estas poetas costarricenses nacidas entre el año 1985 y el año 2000
}

Heirs of thought. These Costa Rican poets who were born between 1985 and 2000 . Herdeiros de pensamento. Esses poetas
costarriquenhos nasceram entre 1985 e 2000.

Mujer, e interesada en todo lo que atañe a mi sexo, he de consagrarle el contingente de mis esfuerzos que, seguramente, en el rol de la ilustración que

la mujer ha alcanzado en los postrimeros días del siglo llamado admirable, será un grano de incienso depositado en el fuego sacro que impulsa el carro del progreso, ... él dará, siquiera, la blanquecina espiral que perfuma el santuario (Matto de Turner, s.f. pág. 169).

Silvia Elena Guzmán-Sierra Investigadora Instituto de Estudios Latinoamericanos Universidad Nacional Costa Rica

Recibido: 15/10/2020 - Aceptado: 15/11/2020

\section{Resumen}

El presente ensayo se realiza como una interlocución con la pensadora, escritora y feminista Clorinda Matto de Turner. En él se relaciona el pensamiento y la práctica creativa de las poetas costarricenses de la generación más joven, aquellas nacidas entre $1985 \mathrm{y}$ el año 2000, para plantear que persisten los retos cotidianos que enfrentan en sus procesos creativos, de publicación de sus obras y de su reconocimiento.

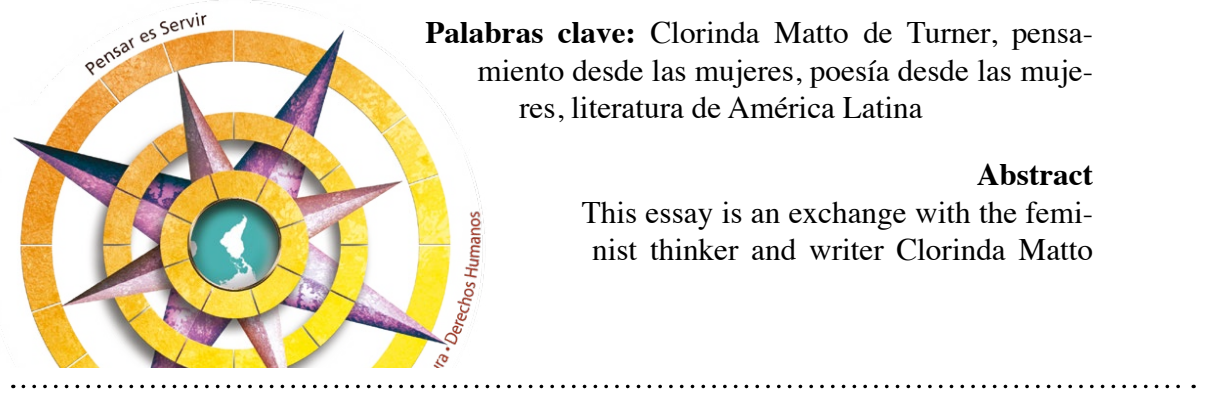


de Turner. It relates the thinking and creative practice of Costa Rican female poets of the younger generation, those born between 1985 and the year 2000, in order to raise the daily challenges they face in their creative processes, the publication of their works and their recognition.

Keywords: Clorinda Matto de Turner, women's thought, women's poetry, Latin American literature

\section{Resumo}

Este ensaio é uma interlocução com a pensadora e feminista Clorinda Matto de Turner. Relaciona o pensamento e a prática criativa dos poetas costarriquenhos da geração mais jovem, aqueles nascidos entre 1985 e 2000, a fim de levantar os desafios diários que eles enfrentam em seus processos criativos, a publicação de suas obras e seu reconhecimento.

Palavras chave: Clorinda Matto de Turner, pensamento feminino, poesia feminina, literatura da América Latina

Soy mujer y escribo porque puedo. La dicha de las palabras, devenida de existencia, pensamiento y sensibilidad se acumula en los dedos para plasmar en este género impuro, mezcla y yuxtaposición, mi derecho a dialogar con el pasado. Este ensayo, género suscrito al libre pensamiento y la estética compleja, que todo tiene que ver con ser mujer y con habitar Nuestra América, me abre su hábitat para reencontrarte, Clorinda Matto de Turner, pionera del pensamiento $\mathrm{y}$ la palabra, en femenino, desde esta América Nuestra, que somos.

Clorinda Matto de Turner: te escribo desde los confines de la creatividad, como heredera de tu labor, $y$ te imagino en un espacio abstracto y cósmico, atenta, escuchando esta historia presente, de las poetas costarricenses nacidas entre el año 1985 y el año 2000. Ya vos lo dijiste, en el tránsito de la historia las mujeres que escriben "luchan día a día, hora tras hora, para producir el libro el folleto el periódico, encarnados en el ideal del progreso femenino Matto de Turner, s.f. pág. 172”.

Hoy, en la América que nos ha visto crecer como ejército de mujeres en la batalla sinuosa de anteponerse a un mundo que nos quiere sumisas, una manada sedienta de ingenio y creatividad escribe y publica en medios digitales e impresos a manera blogs, revistas literarias, antologías y libros individuales. Estos últimos, objeto moderno del conocimiento humano, son un recurso casi inaccesible para las escritoras jóvenes, solo 
cuatro de las escritoras referenciadas en este texto han publicado un libro individual.

Razones sobran para explicar la escasa publicación individual; los altos costos del libro impreso aunado al medio aún machista y adultocéntrico son, quizá, los argumentos principales que se levantan con mayor dureza contra las jóvenes escritoras. Sin embargo, las mujeres poetas, convencidas de la fuerza de nuestra creación, hemos sabido entender que la unión con otras escritoras hace, del pensamiento hecho verso, un objeto de largo alcance y han materializado sus esfuerzos en publicaciones colectivas, venciendo la soledad que ronda a las mujeres con palabra por oficio' ${ }^{1}$. Las poetas jóvenes publicamos juntas, escribimos en la historia un manifiesto práctico de sororidad y lucha colectiva.

Las valientas precursoras que han logrado superar las barreras impuestas a su juventud y así publicar sus propios libros individuales son² Johana Picado Vargas (1989), autora del libro Las cortezas

1 Al decir de Gabriela Mistral.

2 La cuarta poeta con libro individual publicado, soy yo misma, sin embargo, no es mi interés referirme en primera persona singular, sino más bien plural: "nosotras". Por tanto, dejo pasar la referencia a mi publicación. cerebrales (Ediciones Perro Azul), Nathalie Cruz Mora (1987), autora del poemario CeMeYeKa (Amargord Ediciones) y Valeria Morales Núñez (1995), ganadora del segundo lugar del Certamen Literario Brunca de la Universidad Nacional, en su edición 2019 y autora del libro Podemos ser. Curioso resulta que las tres publicaciones individuales citadas se realizaron en el 2019. Johana ha publicado además sus textos en la Antología Poética Taller Laboratorio Tráfico de Influencias, en el 2014.

Por su parte, Nathalie ha sido publicada en más de 15 revistas nacionales e internacionales, Cruz además hace parte de una revista en internet llamada elrepertorio.com, espacio virtual posibilitador del arte latinoamericano que a su vez es trasgresor de fronteras y edades,

“elrepertorio.com es una plataforma web para difusión del arte latinoamericano. Busca agremiar las 7 artes clásicas y algunas otras contemporáneas. Se inspira en el legado del costarricense Joaquín García Monge y su revista Repertorio Americano, pero también busca unir a artistas de las diferentes ramas para crear un diálogo interdisciplinario que enriquezca el quehacer artístico de la región. 
También pretende hermanar países, pueblos y culturas rompiendo el mito generacional del arte." (Cañizales, 2020)

Valeria es la más joven de las autoras ya mencionadas, sin embargo, esto no desmerita la gran labor que ha realizado en el arte poético costarricense, por el contrario, la honra como una de las escritoras jóvenes más prominentes de la generación. Valeria ha sido publicada en la Revista Come Libros (Ed. II y III), y las antologías Certamen Desierto (Ed. Fruit Salas Shaker, 2018), y Y2K (Editorial Estudiantil UCR, 2019). Pero, además, ha utilizado la fuerza de su creatividad, la dulzura de sus ideas y el fuego inacabable por justicia que la describen, para gestionar dos proyectos poéticos colectivos: Antología Cuerpos en movimiento (2020), escrita desde las experiencias de personas migrantes y patrocinada por el fondo Becas Creativas del Ministerio de Cultura y Juventud; y Desacuerdos (2020), antología de mujeres jóvenes escritoras, patrocinada por la Universidad de Costa Rica y publicada por la Editorial Eva.

El año 2020 , año de incertidumbre atroz e individualismo heroico y a su vez egoísta, adjetivos dados por una crisis sanitaria, el año del desconsuelo, el punto más bajo de una sociedad en decadencia que da cuenta de su propia insignificancia. El 2020 pareciera ser el año del agotamiento del sueño de opio sucedido en medio de la descomunal fiesta injusta del capitalismo neoliberal. Nuestra América, cada vez más empobrecida, más abatida, rebosante de conflicto, autoritarismo y represión no ha logrado, querida Clorinda, entre tu siglo y el mío, subir al carro ardiente de un progreso sustancioso para todos los pueblos. Y sin embargo, ahí, en medio de la hecatombe distópica, se publican en Costa Rica tres antologías de mujeres jóvenes poetas y una antología de poesía joven mixta.

La primera de ella es Desacuerdos (Editorial Eva, 2020), gestionada por el proyecto Escritoras Aflorantes, que es dirigido por Katherinne M. Vargas y Valeria Morales Núñez. El proyecto reúne, en 2017, a voces de diecinueve mujeres escritoras y a través de un proceso de edición de sus textos se crea como producto final: la publicación de la antología. Al decir de las compiladoras, en el prólogo de Desacuerdos:

...las mujeres al lápiz renombran, destruyen, crean y preguntan sobre el ser. Mujeres entre los dieciocho y los treinta y cuatro años de edad, trabajadoras, estudiantes,

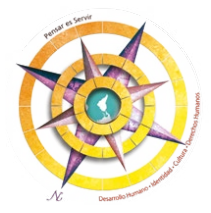


madres, habitantes de zonas urbanas y rurales del país, con experiencia en talleres literarios o no, muestran textos con amplias tensiones, así como estructuras y contenidos de diversas índoles. (Morales Núñes \& Vargas, 2020)

El libro combina la poesía y la narrativa breve, las autoras en orden de aparición en el libro son: Silvia Elena, Fernanda Carrillo, KariOba, Mariela Ch. Herrera, Silya J. Blanco Garita, Alexa Prada Alfaro, Lucía Rodríguez Rodríguez, MGFR, Pamela Calderón Monge, Jennifer Aranda, Sharling Morales Fallas, González Suarez, M, Anamá Rojas, Naomi Quesada Sánchez, Joselyn S. Rojas, Alexa Calderón, Adriana Marín Sandoval, Karen Monge Cascante. Vos que supiste escudriñar tu tiempo, querida Clorinda, sabrás del honor y en tus palabras, "la gloria" de ser parte de esta inconmensurable hazaña.

La cultura de la violencia misógina nos invade, golpea con profunda crudeza, sin embargo, cuando más se desee silenciar las voces de las mujeres, enunciamos más alto en ejercicio polifónico. La antología Los gritos de Medea. Violencia de género en la literatura femenina de hoy, dirigida por Luis Gustavo Lobo Bejarano, gracias a una Beca-Taller del Ministerio de Cultura y Juventud, incluye a poetas de trayectoria en el país como Ana Istarú, Shirley Campbell, Arabella Salaverry, Magda Zavala, Mía Gallegos, Julieta Dobles y Marta Rojas. Pero también las voces frescas de María José Carpio-Ulloa (1994), Jennifer Rojas González (1997), Silvia Pamela Calderón Monge (1995), Shalaisha Barrett Parkinson (1996), Mónica Alvarado Barzuna (1998), Silya J. Blanco Garita (1991) y Yurien Vindas González (1995).

La Colectiva Jícaras hace parte de estas publicaciones colectivas que inauguran la segunda década del siglo XXI, con la antología Atemporal, también patrocinada por una Beca del Ministerio de Cultura y Juventud. En ella, Susana Alvarado Montero, Silvia Pamela Calderón Monge, Melissa Mendiola Vásquez, Ana María Badilla Hidalgo, Carolina Campos Solís, Melissa Valverde Gamboa, Valeria Morales Núñez y Silvia Elena escriben, al decir de la poeta centroamericana Alejandra Solorzano, desde "una habitación nuestra". Dice Alejandra:

«Una habitación nuestra» significa un lugar seguro porque es colectivo y porque se enraíza en el encuentro y en el reconocimiento con las otras. Se trazó a la medida de su sed y de un nuevo giro en la episteme literaria del cómo leerse, de la práctica política que subyace 
en la decisión del cómo publicase, en la forma de producción de su propio libro y en cómo han decidido recorrer en comunidad el camino de las letras. La estética es política, lo sabemos, pero no es coherente si no atraviesa el ejercicio de la autonomía colectivizada de reconocer la individualidad en la diversidad. Las Jícaras es un nuevo círculo concéntrico dentro de la literatura costarricense, musculatura de creación y auto cuido para acompañarse, auto gestionar y movilizar la escritura. (Solorzano, 2020, pág. 4)

Nueva poesía costarricense; antología de poesía joven es el tercer componente de la triada antológica del 2020. Esta fue editada y compilada por el poeta joven Byron Ramírez Agüero. En esta antología se incluyen poemas de varias poetas ya mencionadas, así como poemas de Valeria Villalobos Ramírez, Madeline Soto, María Laura Chaves, Tamara Isaac, Viviana Cortés, Katherine Quirós, Marliz Giraldo, Sianny Barrantes, Carolina Montalvo, Victoria Marín, Milena Chaves M., Alejandra Méndez y Génesis Cubillo.

Según Byron en Madriz (2020): "La nueva poesía costarricense se encuentra más viva que nunca, y la juventud lo sabe; se apropia de sus posibilidades cada día”. Y yo añado, las mujeres jóvenes escritoras costarricenses, mis compañeras de camino y causa, hemos encontrado la llave hermosa de rendir el ego artístico ante la belleza de la metáfora en colectivo, juntas nos sabemos fuertes y continuamos.

Como antecesoras de las mencionadas antologías se pueden mencionar los libros: Antología de poesía joven costarricense (Casa de Poesía, 2016), Antología Miércoles de Poesía (2018), Antología Poética Taller Laboratorio Tráfico de Influencias (2014), Antología Verso diverso (2018), Antología Bitácora abierta: 31 latidos en el andén (Editorial Poiesis, 2015), Antología Certamen Literario Brunca (2018), Antología Certamen Desierto (2018), Antología Y2K (2019)

Además, las poetas han publicado en revistas nacionales e internacionales entre las que destacan: Revista Liberoamérica, Revista Toxicxs, Revista Larvaria, Revista Materia Escrita, Revista Campus de Plumas, Revista Come libros y Círculo de poesía. En estas publicaciones se suman los nombres de Katherine Quirós Bonillasusan (1996), Joselyn López Rojas (1992) y Guadalupe Vargas Díaz (1993).

\section{Herederas del pensamiento}

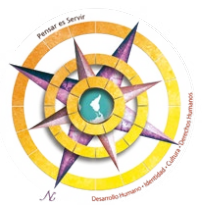


El blog como espacio virtual, autogestionado e íntimo es también un recurso utilizado por las escritoras, quienes sobrepasan la barrera tiempo espacio, sin certeza de quienes son sus lectoras y lectores, ellas perseveran, exponen sus verdades, imágenes y versos. De las poetas ya referidas son tres las que utilizan el espacio virtual a favor de su arte: Melissa Mendiola Vásquez (nicaragüense-costarricense, 1988) gestiona Melissavitrubio.hom.blog, Shalaisha Barrett Parkinson levanta su voz en su blog "La coleccionista de espejos" y Naomi Quesada Sánchez nos abre el corazón de su creatividad en "Errataraya blog".

Así, una generación de mujeres, tal y como lo auguraste, ancestra cabal, valiente luz de nosotras las escritoras latinoamericanas, seguimos "con la planta herida por los abrojos del camino y la frente iluminada por los resplandores de la fe en los destinos humanos" (Mato de Turner, S.f., pág. 172), continuamos laborando. A vos, al recuerdo de las mujeres de letras que ya no están, a las mujeres que abrieron camino que aún siguen vivas, y a ellas mis compañeras que son refugio y referente, este poema de furia y esperanza.

\section{Revancha}

esta

nace del páncreas

- - en hijitos de colores

azulmarinos- -

para no callar

y recorre el cuerpo desbordándonos

en veraneras

flores

por nuestras bocas y nuestros ojos.

¡ay Ceniza de desencuentro!, que sos lo mismo que los miedos,

Ceniza de dependencia,

de -- quédate callada maricona-qué pena, Ceniza, te dejamos puerta afuera, acá dentro nos armamos la revolución, reímos voraces de un encuentro o dos o tres o los que la fortuna quiera.

los milenios nos reclaman y volvemos a la vida, menstruantes, tristes cuando sea necesario, juntas, eso sí, a pesar de todos los mañanas. (Silvia Elena, 2020, pág. 16) 


\section{Referencias}

Cañizales, M. (2020). ¿Quiénes somos? Recuperado de http://repertorioamericano.org/

Madriz, A. (2 de noviembre de 2020). Antología Poética reúne obras de 40 jóvenes costarricenses. El periodico CR, págs. Recuperado de HYPERLINK "https://elperiodicocr.com/antologia-poetica-reune-obras-\%09de-40-" https://elperiodicocr.com/antologia-poetica-reune-obras-de-40-jovenes-costarricenses/

Mato de Turner, C. (S.f.). Las obreras del pensamiento en la América del Sur (1895). En Aves sin nido (págs. 169179). Editorial Sendes Universitat Jaume I de Castellón.

Guzmán-Sierra, S. (2020) Revancha. En Morales, V., Vargas, K.,comp. Desacuerdos. Costa Rica: Editorial Eva.

Silvia Elena. (2020). Revancha. En V. Morales Núñez, Vargas, K , Desacuerdos (pág. 16). Heredia, Costa Rica: Editorial Eva.

Solorzano, A. (2020). Prólogo: Una habitación Nuestra. En C. Jícaras, Atemporal (págs. 3-5). Costa Rica: Colectiva Jícaras. 